\title{
The erythroid-specific protein cGATA-1 mediates distal enhancer activity through a specialized $\beta$-globin TATA box
}

\author{
Timothy C. Fong and Beverly M. Emerson ${ }^{1}$ \\ Regulatory Biology Laboratory, The Salk Institute for Biological Studies, La Jolla, California 92037 USA
}

The erythroid-specific protein cGATA-1 regulates the chick $\beta$-globin gene through GATA sequences present at the canonical TATA location in the promoter as well as in the distal 3 ' enhancer. We have analyzed $\beta$-globin transcription in transfected erythroid cells and in erythroid extracts to determine whether cGATA-1 binding at $-\mathbf{3 0}$ regulates promoter or enhancer activity. The interaction of both cGATA-1 and TFIID at different times with the -30 GATA site is required for efficient $\beta$-globin expression in vivo, and the GATA enhancer site can functionally replace the TATA element in the $\beta$-globin promoter. TFIID initiates transcription in vitro by complexing with adaptor proteins and displacing cGATA-1 from the -30 GATA site. Mutations that abolish TFIID binding to the -30 GATA box inactivate the promoter, whereas elimination of cGATA-1 binding to this site selectively diminishes enhancer-dependent transcription. We propose that interaction of cGATA-1 with the distal 3' enhancer and the specialized TATA box confers erythroid specificity to the initiation complex by mediating promoter-enhancer communication. Thus, one mechanism of action for tissue-specific proteins that recognizes noncanonical TATA motifs is to enable TFIID to be regulated by distal control elements. In this way, the initiation complex can be responsive to specific regulators that may not recognize a canonical TFIID-TATA structure.

Key Words: Promoter-enhancer interaction; TATA box/TFIID; erythroid transcription factor, GATA-1; $\beta$-globin gene transcription]

Received December 30, 1991; revised version accepted February 3, 1992.

The chick $\beta$-globin gene is part of a multigene family whose individual members are expressed at different stages of erythroid development. Transcription of the embryonic globin genes occurs only in primitive red blood cells (RBCs), whereas expression of the adult globin genes is restricted to definitive erythrocytes. This switch in red cell lineages occurs by about day 5 of chick embryogenesis (Bruns and Ingram 1973; Brown and Ingram 1974; Chapman and Tobin 1979). The regulation of $\beta$-globin gene activity is achieved primarily through changes in chromatin structure (Stalder et al. 1980; McGhee et al. 1981) and the interaction of specific DNAbinding proteins with the $5^{\prime}$ promoter and $3^{\prime}$ enhancer (Emerson et al. 1985, 1987, 1989; Plumb et al. 1986; Evans et al. 1988; Lewis et al. 1988). These two control regions bind multiple proteins, consisting of tissue-specific and general factors, whose composition changes during erythroid maturation. Recently, an in vitro transcription system was devised using extracts from primary RBCs isolated at different stages of embryonic development. In this soluble system, the $\beta$-globin gene is expressed in a manner similar to that observed with the

\footnotetext{
${ }^{1}$ Corresponding author.
}

endogenous gene in red cell nuclei. These experiments demonstrated that transcriptional regulation is achieved by a combination of activator proteins whose concentration is highest in expressing RBCs of the appropriate developmental stage. As erythroid maturation proceeds, the activity of a potent repressor, PAL, increases severalfold and shuts off $\beta$-globin expression by binding the promoter and counteracting the effects of the activator proteins (Emerson et al. 1989). Chromatin reconstitution experiments have shown that the interaction of these multiple transcription factors with the $\beta$-globin promoter induces a nuclease hypersensitive site similar to the developmentally regulated structure observed in definitive RBCs (Emerson and Felsenfeld 1984). Thus, several important aspects of $\beta$-globin gene regulation can be reproduced by using in vitro systems.

One critical control region that has not been analyzed in vitro is the $3^{\prime}$ enhancer. This region is required for $\beta$-globin expression in transfected RBCs (Hesse et al. $1986)$ yet is not functional in the soluble transcription system (B.M. Emerson, unpubl.). Enhancer activity in vivo is dependent on DNA sequences that interact with several proteins, including the erythroid-specific enhancer-binding factor cGATA-1 (Emerson et al. 1987; Evans et al. 1988; Reitman and Felsenfeld 1988). This 
protein has been purified $(37 \mathrm{kD})$ and recently cloned from murine (mGATA-1), chick (cGATA-1), and human (hGATA-1) erythroid cells (Evans and Felsenfeld 1989; Tsai et al. 1989; Trainor et al. 1990|. GATA-1 is highly tissue specific, and its binding site is found in the control regions of many erythroid genes (Evans et al. 1988; Plumb et al. 1989). Experiments with chimeric mice have shown that mutations in the GATA-1 gene result in a block in erythroid maturation. GATA-1, therefore, may represent a "switch" protein involved in the differentiation of the erythroid lineage (Pevny et al. 1991).

Recent studies indicate that GATA-1 is part of a multigene family (Wilson et al. 1990; Yamamoto et al. 1990 . One member of this family, GATA-3, is highly expressed in $\mathrm{T}$ lymphocytes and brain. This protein was first implicated in the regulation of $T$-cell-specific genes because the GATA consensus-binding site is located in the enhancer regions of the $\alpha$ and $\delta$ chains of the T-cell receptor [TCR (Ho et al. 1989, 1991; Winoto and Baltimore 1989; Redondo et al. 1990)]. More recent functional experiments demonstrate that both mouse and human GATA-3 can trans-activate expression of the human TCR $\delta$ gene through the GATA sequence in the enhancer (Ko et al. 1991). Thus, the GATA family of proteins plays a critical role in regulating tissue-specific enhancer activity in several different cell types. As a first step in understanding the mechanism of action of these important regulatory proteins, we have analyzed the function of the crythroid-specific cGATA-1 in $\beta$-globin gene expression.

Here, we show that purified cGATA-l binds specifically to both the $3^{\prime}$ enhancer and to the specialized TATA sequence (GATA at -30 ) in the $\beta$-globin promoter, suggesting that promoter-enhancer communication may be mediated through this element. Mutations in the -30 GATA box that differentially abolish the binding of either cGATA-1 or TFIID have been analyzed in vivo and in vitro. These results indicate that TFIID is necessary for transcriptional initiation, and cGATA-1 regulates the ability of the distal enhancer to activate the promoter. Both proteins function separately through the same DNA-binding site and can displace each other, depending on their relative concentrations. Moreover, we find that non-DNA-binding proteins, or adaptors, are required to mediate this effect. Thus, a critical step in the tissue-specific regulation of the $\beta$-globin gene is the establishment of enhancer-promoter interaction mediated, in part, by cGATA- 1 bound to -30 . Once this interaction is stable, TFIID in combination with adaptor proteins can displace cGATA-1 from the - 30 GATA site to form an active initiation complex.

\section{Results}

cGATA-1 interacts with both the promoter and enhancer regions of the chick $\beta$-globin gene

To analyze how the distal $\beta$-globin enhancer may affect promoter function, we initially performed DNase protection experiments on the promoter region using purified
cGATA-1. Previous studies have shown that at least eight proteins interact with this control region (Lewis et al. 1988; Emerson et al. 1989), including the TATA box. When purified cGATA-1 was analyzed on the $\beta$-globin promoter in DNase protection experiments, only the GATA sequence at -30 was bound by protein (Fig. 1, right). The protected region, CGGAGGCGATAAA, contains the core sequence GATAAA, which is also present in the GATA-l-binding site within the $\beta$-globin enhancer between +1891 and +1906 (Fig. 1, left). Thus, cGATA-1 interacts with a GATA element in both the enhancer and promoter at the canonical TATA box position. To confirm this observation, we found that cGATA- 1 binding to its $5^{\prime}$ and $3^{\prime}$ sites was specifically abolished in the presence of competing oligonucleotides to either the promoter or enhancer GATA sequences (data not shown). This supports the idea that these two sequences are recognized by the same DNA-binding domain within the CGATA-1 protein.

Conversion of the - 30 GATA sequence to a canonical TATA box abolishes CGATA-1 binding

We examined the binding ability of CGATA-1 on $\beta$-globin promoters containing mutated sequences in the - 30 GATA box by a gel mobility-shift analysis. Interaction with the normal sequence at -30 (GAGGCGATAAAAGT) was compared with that of a GG mutated sequence (GAGGCGAGGAAAGT) and a canonical TATA box (GAGGCTATAAAAGT). As shown in Figure $2 \mathrm{~A}$, the cGATA-1 protein binds specifically to the GATA sequence (lanes 2,3) whereas no interaction is observed with either the $\beta$-globin TATA (lane 8), adenovirus TATA (Adeno TATA; lane 10), or GG (lane 12) oligonuclcotides. Moreover, in oligonucleotide competition experiments the cGATA-1/GATA DNA complex is inhibited by GATA (lane 4) but not by TATA (lane 5) or GG (lane 6) oligonucleotides. Thus, a mutation of the GATA sequence to a canonical TFIID recognition site completely abolishes the binding of cGATA-1. This analysis was also used to examine the interaction of TFIID with these oligonucleotides, as shown in Figure $2 \mathrm{~B}$. Through the use of bacterially expressed yeast TFIID, binding is observed to both the adenovirus major late promoter (AdMLP) (lanes 2,3) and mutated $\beta$-globin TATA (lane 8 ) sequences. In contrast to cGATA-1, however, cloned TFIID binds only weakly to the $\beta$-globin GATA oligonucleotide (lane 10) and is completely abolished on the oligonucleotide containing the GG mutation (lane 12). TFIID interaction with the $\beta$-globin TATA sequence is specifically inhibited with competitor oligonucleotides to the TATA site (lane 4), whereas competition with either GATA (lane 5) or GG (lane 6) oligonucleotides has no effect on TFIID binding. Taken together, these experiments indicate that conversion of the GATA site to a canonical TATA box specifically inhibits the interaction of cGATA-1 and that mutation of TATA to GATA severely weakens the binding of cloned TFIID. The interaction of both cGATA-1 and TFIID is eliminated by mutation of GATA to GAGGA. 


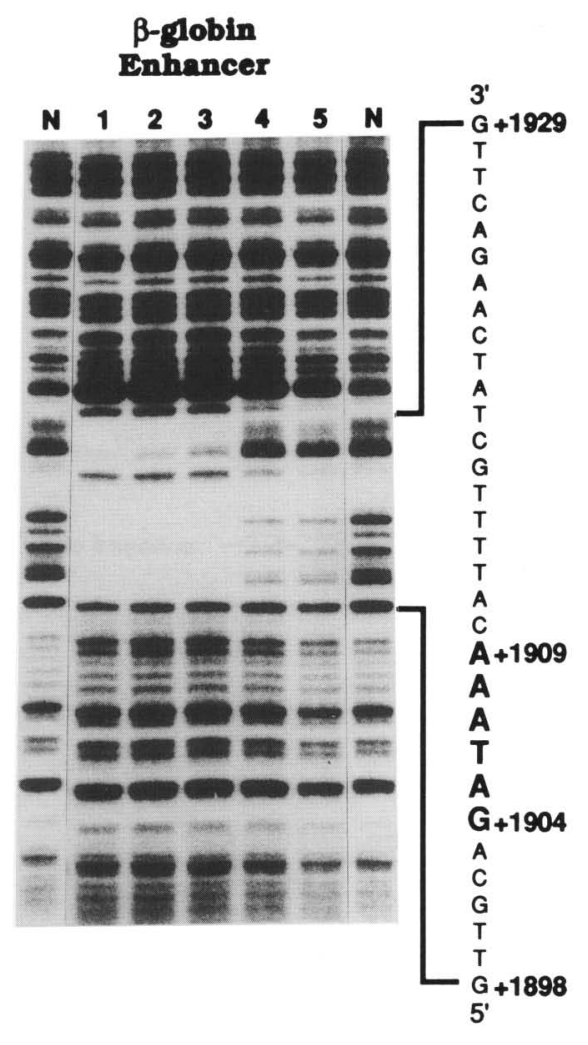

\section{B-globin Promoter}

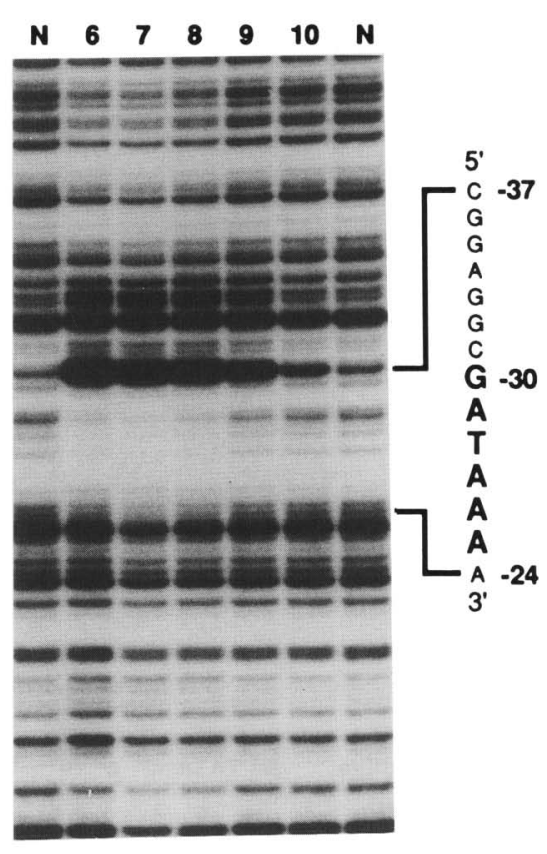

Figure 1. The cGATA-1 protein binds GATA sequences in the $5^{\prime}$ promoter and 3 '-enhancer of the chick $\beta$-globin gene. DNase I protection analysis of cGATA-1 protein on the chick $\beta$-globin enhancer and promoter. A 729-bp BamHI-NdeI $(+1623$ to +2102$)$ enhancer fragment and a 297-bp NcoI-PstI promoter fragment $(-214$ to +83$)$ were ${ }^{32}$ P-end-labeled and incubated with oligonucleotide affinitypurified cGATA-1 protein from 11-day chick RBCs. Purified cGATA-1 was added in the following amounts: enhancer fragment, $1.40,0.70,0.35,0.18$, and $0.09 \mu \mathrm{g}$ (lanes $1-5$, respectively); promoter fragment, $1.40,0.70,0.35,0.18$, and $0.09 \mu \mathrm{g}$ (lanes $6-10$, respectively). (Lane N) DNase I digest of either the enhancer or promoter fragment with no added protein.

cGATA-1 binding to the - 30 GATA box is required for efficient enhancer-dependent transcription

To examine the functional role of cGATA-1 interaction with the promoter, we compared the activity of the normal promoter sequence at -30 with that of the GG and TATA mutations, which no longer bind cGATA-1 by transfection into primary cultures of chick embryonic RBCs. In this analysis the modified and unmodified $\beta$-globin promoters were linked to the chloramphenicol acetyltransferase (CAT) gene and the $3^{\prime} \beta$-globin enhancer. Conditions for transfection were according to the procedure of Jackson et al. (1989). As shown in Figure 3, $\beta$-globin-CAT constructs containing the unmodified promoter and $3^{\prime}$ enhancer (AcatE30) are efficiently expressed in 11-day chick erythrocytes relative to a Rous sarcoma virus promoter-CAT gene (RSV-CAT) control. If the $3^{\prime}$ enhancer is deleted from these $\beta$-globin-CAT constructs, leaving only a functional promoter (Acat), transcription is almost completely abolished $(6.1 \%)$. CAT constructs having a functional enhancer but a promoter carrying the GG mutation in the GATA box (AcatE/GG) show severely reduced transcriptional efficiency $(16.8 \%)$, presumably because neither cGATA-1 nor TFIID can bind to this sequence (Fig. 2). Interestingly, when the $\beta$-globin - 30 GATA sequence is mutated to a canonical TATA box (AcatE/TATA), expression levels of $\beta$-globin-CAT constructs are decreased by $70 \%$ relative to the wild-type promoter (AcatE30) even though TFIID binds strongly to this site (Fig. 2B). This result indicates that TFIID binding to a TATA element is not sufficient for high levels of enhancer-dependent $\beta$-globin expression and that cGATA- 1 binding at -30 is required to mediate this effect.

The cGATA-1 enhancer-binding site can function as a TATA element when placed in the promoter

Because cGATA-1 can interact at sites in both the promoter and enhancer, we constructed $\beta$-globin templates containing the enhancer GATA-1-binding site (TTGCAGATAAACAT) in place of the GATA sequence in the promoter. In this way, we wished to determine whether an enhancer region that is crucial for tissue-specific expression can also function as a TATA element. $\beta$-Globin genes containing this substitution were examined by DNase protection and by transfection into primary erythroid cells. The protein interaction pattern obtained by DNase protection indicates that CGATA-1 can efficiently bind to the GATA enhancer sequence when placed at -30 and that this complex does not alter the binding of any other promoter factor (data not shown). To assess whether the site through which cGATA-1 regulates the enhancer can also direct transcription, $\beta$-globin-CAT constructs containing the GATA(Enh)substituted promoter and the $3^{\prime}$ enhancer were analyzed for expression in 11-day chick erythrocytes. As shown in Figure 3, these constructs (AcatE/RIV) are expressed with $63 \%$ the efficiency of those containing the unmodified GATA box (AcatE30). These results demonstrate that a tissue-specific enhancer element can functionally 
Figure 2. Gel mobility-shift analysis of cGATA-1 and TFID interaction with GATA and TATA sequences. Affinity-purified cGATA-1 and bacterially expressed yeast TFIID were incubated with ${ }^{32} \mathrm{P}$-end-labeled oligonucleotides containing modifications of the - 30 GATA sequence: TATA (TATAAA) and GG (GAGGAAA). Oligonucleotides containing the canonical TATA sequence from the AdMLP were also used. (A) cGATA-1 protein binds specifically to GATA sequences. Two nanograms of cGATA-1 protein was incubated with the following 5 , 32 $\mathrm{P}$-labeled oligonucleotides (0.025-0.05 ng): GATA (lanes 3-6; lane 2 contained $1 \mathrm{ng}$ of cGATA-1); TATA (lane 8); Ad TATA (lane 10); and GG (lane 12). (Lanes $1,7,9,11)$ Reactions with no protein. Oligonucleotide competition experiments (lanes 4-6) were performed by preincubating cGATA-1 protein with $7.5 \mathrm{ng}$ of unlabeled oligonucleotide to GATA (lane 4), TATA (lane 5), or GG (lane 6) sequences. (B) TFIID binds specifically to TATA sequences. Five nanograms of yeast TFIID was incubated with the following $5^{\prime}{ }^{32} \mathrm{P}$ labeled oligonucleotides (0.025-0.05 ng): $\mathrm{Ad}$ TATA (lanes 3-6; lane 2 contained 2.5 of $\mathrm{ng}$ TFIID); TATA (lane 8); GATA (lane 10); and GG (lane 12). (Lanes 1,7,9,11) Reactions with no protein. Oligonucleotide competition experiments (lanes 4-6) were performed by preincubating TFIID with $7.5 \mathrm{ng}$ of unlabeled oligonucleotide to TATA (lane 4), GATA (lane 5), or GG (lane 6) sequences.

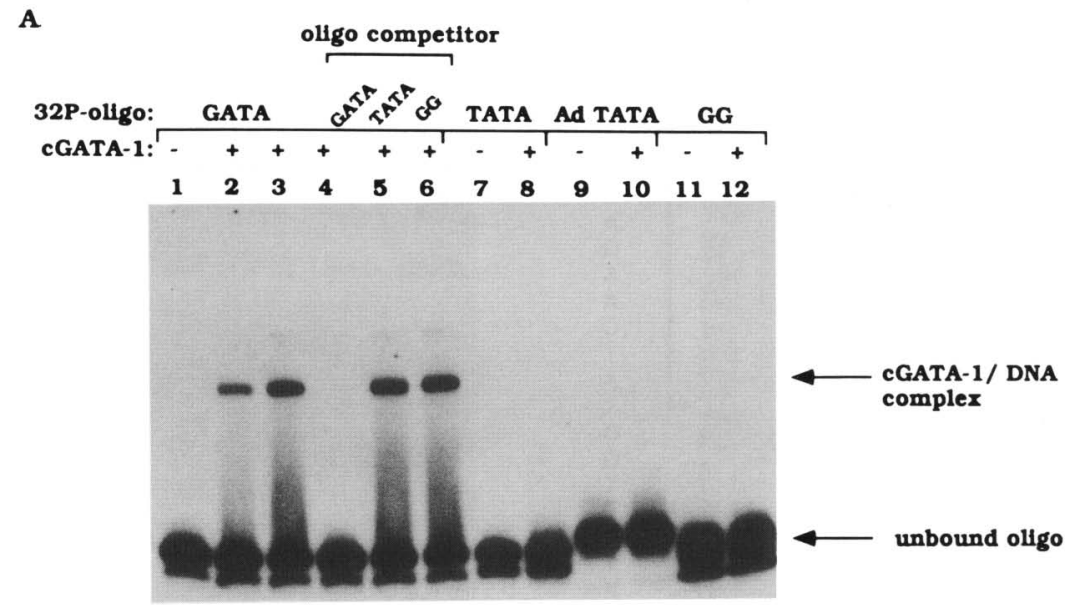

B

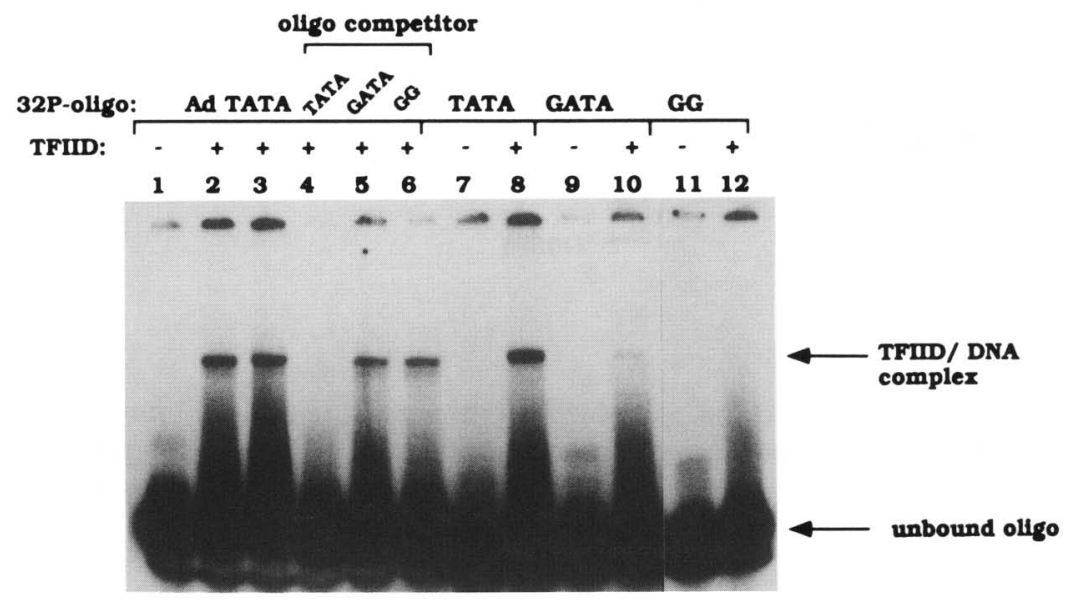

replace the $\beta$-globin TATA box and mediate the activity of erythroid TFIID.

The lower transcriptional activity of AcatE/RIV, relative to AcatE30, suggests that although cGATA-1-binding sites in both the promoter and enhancer can function as TATA elements, they are not absolutely equivalent. For example, TFIID may bind more tightly to the wildtype GATA environment at -30 . Mutating this site to the GATA enhancer sequence may diminish this interaction and result in a slightly lower level of expression.

Figure 3. In vivo activity of wild-type and modified $\beta$-globin promoters directing the expression of bacterial CAT genes in transfected primary 11-day RBCs. Primary RBCs $\left(3 \times 10^{7}\right.$ to $\left.5 \times 10^{7}\right)$ were transfected with 3 $\mu \mathrm{g} / \mathrm{ml}$ of DNA as described by Jackson et al. (1989). Following a 48-hr incubation at $37^{\circ} \mathrm{C}$, the cells were processed and assayed for CAT activity. (RSV-CAT) Plasmid con-

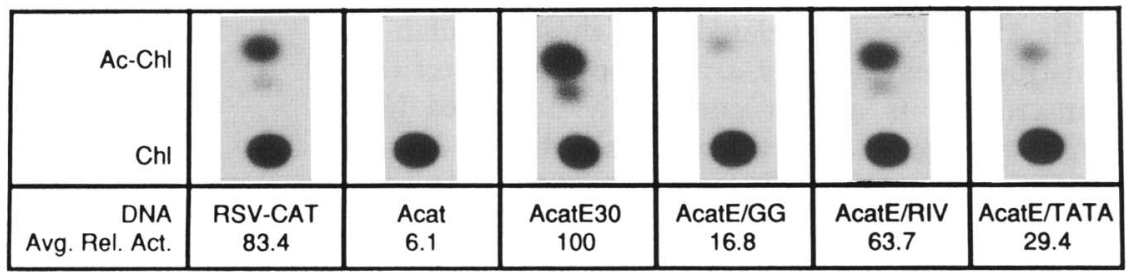
taining the RSV LTR directing CAT expression. (Acat) Wild-type $\beta$-globin promoter $(-1000$ to +43$)$ linked to the CAT gene with a deleted 3' $\beta$-globin enhancer. (AcatE30) Wild-type $\beta$-globin promoter linked to the CAT gene with the $3^{\prime} \beta$-globin enhancer $/+1814$ to +2231 ). (AcatE/GG) AcatE30 with GG mutation at the -30 GATA box. (AcatE/RIV) AcatE30 with cGATA-1 enhancer sequence (region IV) substitution at the -30 GATA box. (AcatE/TATA) AcatE30 with TATA mutation in the - 30 GATA box. The relative activity for each construct was determined by dividing the percent $\left[{ }^{14} \mathrm{C}\right]$ chloramphenicol conversion for each mutant by the percent conversion for the wild-type promoter with enhancer (pAcatE30). The average relative activities were calculated from four experiments containing three to four replicates of each construct. 
However, the observation that the GATA(Enh)-substituted construct is more active than one containing a normal TATA box (AcatE/TATA) further supports the notion that cGATA-1 must interact with both the enhancer and the -30 GATA site for efficient expression to occur.

cGATA-1 binding at -30 is not required for $\beta$-globin promoter activity in vitro

$\beta$-Globin promoter mutations that decrease CAT expression in transfected erythroid cells (Fig. 3) may do so by either lowering promoter activity itself or by affecting the ability of this element to respond to the distal enhancer. To discriminate between these two possibilities, we examined $\beta$-globin templates containing mutations in the -30 GATA box for transcriptional activity in vitro. In most in vitro systems, gene expression levels are determined solely by promoter strength because distal enhancer elements are not functional. In our case, the chick $\beta$-globin gene is transcribed in erythroid extracts with equal efficiency in the presence or absence of its 3 ' enhancer. Therefore, the in vitro transcription levels obtained from $\beta$-globin genes mutated at the -30 GATA box are a measure of promoter activity rather than promoter-enhancer interactions. In contrast, expression levels obtained from genes transfected into erythroid cells are dependent upon both promoter strength and enhancer activity.

In vitro transcription experiments were carried out using erythroid extracts obtained from 11-day chick embryonic RBCs as described previously (Emerson et al. 1989|. The parental template used in these studies contains the entire $1.5-\mathrm{kb}$ chick $\beta$-globin gene with 0.4 and $1.5 \mathrm{~kb}$ of $5^{\prime}$ - and $3^{\prime}$-flanking sequences, respectively. These sequences comprise the $5^{\prime}$ - and $3^{\prime}$-nuclease hypersensitive regions as well as the $3^{\prime}$ enhancer. A $17-\mathrm{bp}$ BamHI-Xmal linker was inserted at +46 in the $5^{\prime}$-untranslated leader to distinguish in vitro-synthesized globin RNA from the endogenous globin message present in the RBC transcription extracts. All reactions were analyzed for $\beta$-globin synthesis by the $S 1$ nuclease technique, using a probe that detects both endogenous and newly generated transcripts.

As shown in Figure 4, $\beta$-globin genes containing the GG mutation, which abolishes both cGATA-1 and TFIID binding to the -30 GATA box (Fig. 2), are transcriptionally inactive in 11-day RBC extracts (lane 2), whereas high levels of RNA synthesis are obtained with the unmodified template (lane 1). In contrast, when the -30 GATA box is mutated to a normal TATA sequence, which no longer interacts with cGATA-1 but binds TFIID with much higher affinity (Fig. 2), transcription levels remain the same (lane 4). This suggests that when TFIID can interact efficiently at -30 through a TATA sequence, cGATA-1 is not required for promoter activity. This presumably reflects the greater affinity of TFIID for TATA than for GATA sequences (Fig. 2). $\beta$-Globin genes containing the cGATA-1 enhancer-binding site (region IV) in place of the - 30 GATA sequence can di-

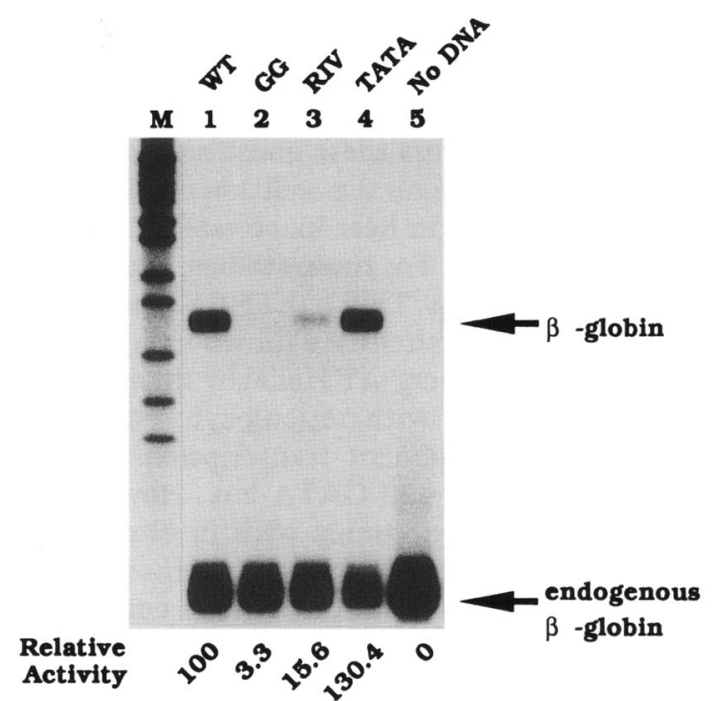

Figure 4. In vitro transcription of $\beta$-globin promoters containing modified TATA boxes. Transcription reactions were performed as described in Materials and methods. The template activities of $\beta$-globin DNA $(0.5 \mu \mathrm{g} /$ reaction) containing wildtype or mutated - 30 GATA sequences were compared using nuclear transcriptional extracts from 11-day embryonic RBCs $(15 \mu \mathrm{l} /$ reaction; lanes $1-5)$. These reactions are shown as follows: WT, pUCABC/ $\Delta 1$ (lane 1); $\Delta 1 / \mathrm{GG}$ (lane 2); $\Delta 1 /$ RIV (lane 3); $\Delta$ I/TATA (lane 4); and no DNA (lane 5).

rect correctly initiated transcription in erythroid extracts (lane 3), although to a lower extent than that observed in transfected erythroid cells (Fig. 3). In all $\beta$-globin constructs the $3^{\prime}$-enhancer region can be deleted with no effect on expression levels in erythroid transcription extracts (data not shown). This is consistent with the observation that distal enhancer regions are not normally required in in vitro transcription systems using naked DNA templates.

A comparison of transcriptional levels obtained in vivo (Fig. 3) and in vitro (Fig. 4) indicates that the inactivity of $\beta$-globin genes containing the -30 GG mutation is most likely because TFIID is unable to bind the promoter and there is no initiation. Unlike the situation in vivo, where low-level transcription is observed with the GG mutation (Fig. 3), there is no activity in vitro, presumably because the enhancer does not function under these conditions and expression is entirely promoter dependent. Thus, the GG mutational effects can be attributed to an inactive promoter. In contrast, $\beta$-globin genes containing the TATA mutation are much more active in vitro than in vivo, relative to the normal GATA template. Because this sequence change does not lower the activity of the promoter, the decreased expression in vivo must be the result of a disruption in promoterenhancer interaction, which requires the binding of cGATA-1 at -30 .

TFIID regulates $\beta$-globin promoter activity through the -30 GATA box in vitro

Because cGATA-1 and TFIID must interact through the 
same initiation element at -30 , we asked what relation these proteins have to one another and whether cGATA-1 itself can function as TFIID or act cooperatively with it. To address these questions we used an in vitro system that relies on the addition of TFIID to complement transcription in heat-inactivated HeLa extracts (Nakajima et al. 1988). For these studies, rabbit reticulocyte-translated human TFIID (hTFIID) and cGATA-1 were used as protein sources. As shown in Figure 5, heatinactivated HeLa extracts $\{\Delta \mathrm{T}$ HeLa) by themselves (lane 2) or in combination with reticulocyte control lysate (lane 3) fail to complement transcription on $\beta$-globin genes containing the -30 GATA box. However, when these extracts are programmed with in vitro-translated hTFIID, $\beta$-globin genes are expressed efficiently (lanes $4,5)$. In contrast, transcription reactions complemented with in vitro-translated cGATA- 1 fail to express $\beta$-globin genes (lanes 6,7) or stimulate TFIID activity (lane 8) even though this protein binds the - 30 GATA sequence with high affinity (Fig. 2A). As a control, in vitro-translated Jun protein was also tested and found to have no TFIID stimulatory (lane 9) or complementing (lane 10) activity on $\beta$-globin gene templates. These results indicate that cGATA-1, by itself, does not function as an erythroidspecific TFIID factor when bound to the $\beta$-globin initiation element.

Because HeLa extracts that are heat inactivated can be fully reconstituted for transcriptional activity by the ad-

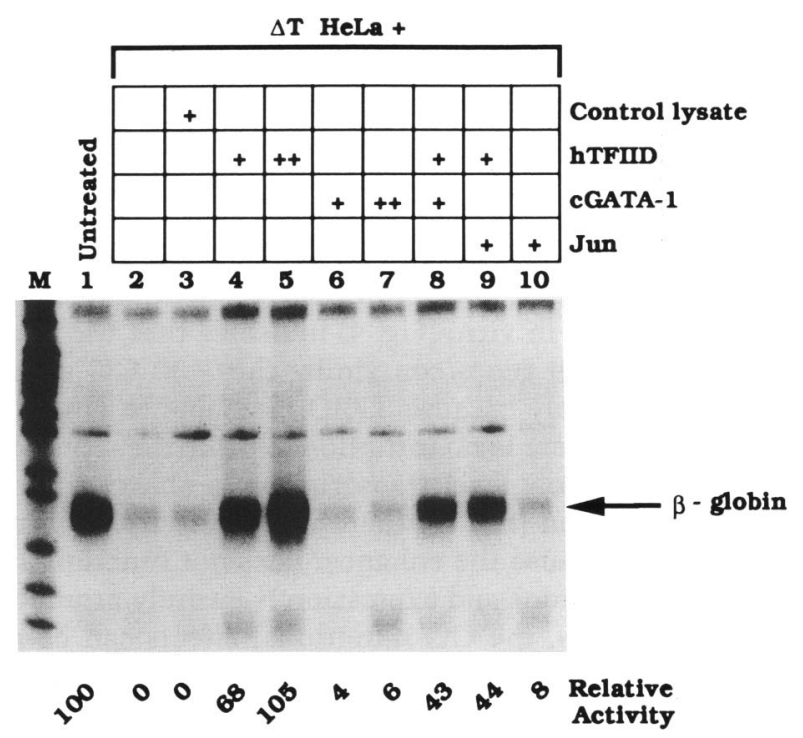

Figure 5. TFIID functions through a cGATA-1/DNA complex to activate transcription from -30 GATA boxes. Complementation of heat-inactivated HeLa extracts with in vitro-synthesized TFIID and CGATA- 1 on the -30 GATA promoter $\{\Delta 1 /$ GATA). (Lane 1) Untreated HeLa extract. (Lane 2) Heat-treated HeLa extract ( $\triangle \mathrm{T}$ HeLa) alone and with the following additions: $2.5 \mu \mathrm{l}$ of control lysate (lane 3 ); 2.5 and $10 \mu \mathrm{l}$ of in vitro-translated hTFID (lanes 4,5 ); 2.5 and $10 \mu$ l of in vitro-translated cGATA-1 (lanes $6-7) ; 2.5 \mu \mathrm{l}$ of hTFIID plus $2.5 \mu \mathrm{l}$ of cGATA-1 (lane 8 ); $2.5 \mu \mathrm{l}$ of hTFIID plus $2.5 \mu \mathrm{l}$ of Jun (lane 9); $2.5 \mu \mathrm{l}$ of Jun (lane 10). dition of a single protein, cloned TFIID, this demonstrates that TFID has been selectively inactivated and is the only protein required for complementation of $\beta$-globin transcription in this assay. This indicates that the $\beta$-globin promoter is TFIID dependent even though it contains a noncanonical TATA box that interacts with an erythroid-specific protein, cGATA-1. The observation that cGATA-1 cannot restore transcription in an assay that is specific for TFIID activity suggests that it serves a different function at the initiation site. Because the GATA protein is part of a multigene family, the members of which are presumably present in most cell types, it is formally possible that they bind to the $\beta$-globin promoter and activate transcription in HeLa extracts. How ever, these nonerythroid GATA proteins do not obviate the requirement for TFIID because they are not sufficient to restore transcription if TFIID has been inactivated.

Taken together, these results suggest that TFIID is a necessary component of $\beta$-globin promoter activation in vitro and that the major role of cGATA-1 is not to function as a direct transcriptional activator when bound at -30 but, rather, to mediate enhancer activity, potentially by establishing an interaction between the distal enhancer and promoter control elements.

TFIID requires adaptor proteins to interact with the - 30 GATA box and to displace CGATA-1 from this site

In crythroid cells TFIID must apparently recognize a cGATA-1/DNA complex at -30 . To determine whether these two proteins can form a stable association with each other on GATA-binding sites we conducted gel mobility-shift experiments using affinity-purified cGATA-1 and bacterially expressed hTFIID. As shown in Figure 6A, hTFIID binds very weakly to ${ }^{32}$ P-labeled GATA oligonucleotides (lane 3) in contrast to cGATA-1 (lane 2). When both proteins are combined, no detectable mobility shift of the cGATA-1/GATA complex is observed (lanes 4,5), indicating that cloned hTFIID does not form a stable complex with cGATA-1. However, as shown in Figure 6B, when hTFIID is added to a non-DNA-binding protein fraction from erythroid cells that is likely to contain factors that mediate protein-protein interactions, a stable hTFIID complex is formed on GATA oligonucleotides (lanes 4-6). This complex is higher in mobility than hTFIID alone (lane 2), indicating that at least one protein in this "adaptor" fraction is associated with hTFIID and greatly increases its affinity for GATA sites. The adaptor fraction displays minimal DNA-binding activity itself and contains little, if any, cGATA-1 protein (lane 3) even over a broad concentration range (data not shown). This demonstrates that cGATA-1 is not required for hTFIID to interact efficiently with GATA sites. Interestingly, when the adaptor fraction is combined with cGATA-1, no change in mobility of the cGATA-1/GATA complex is observed but there is a significant decrease in cGATA-1 binding (lanes 7-9). Moreover, the addition of cGATA-1 to the hTFIID-adaptor 
A

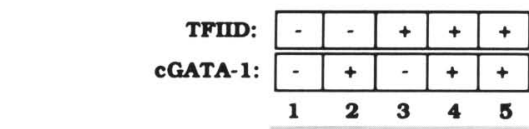

C

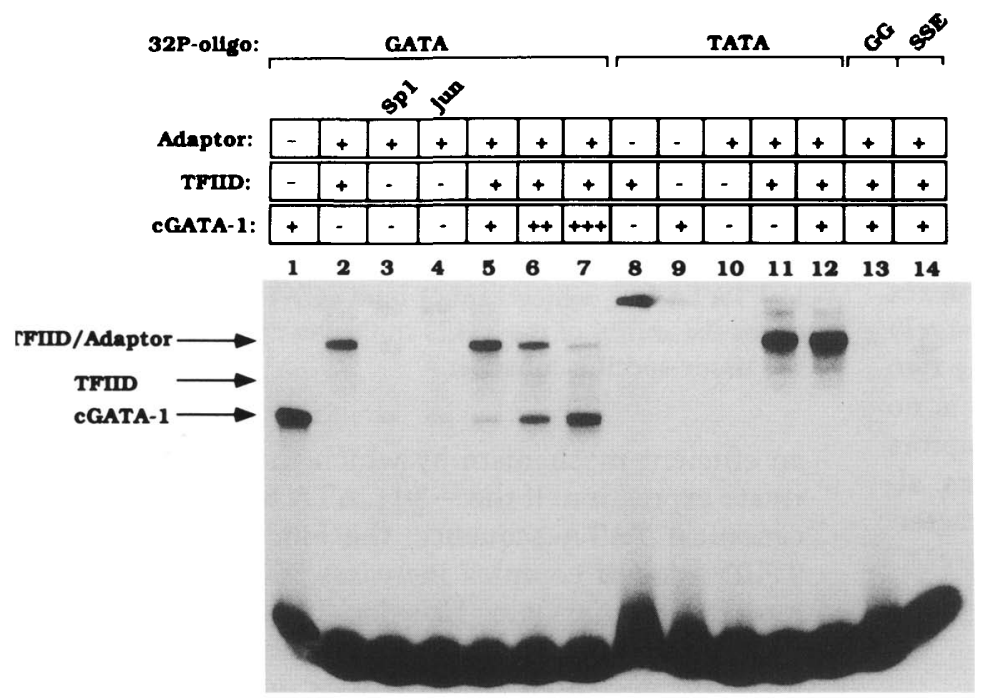

$\mathbf{B}$

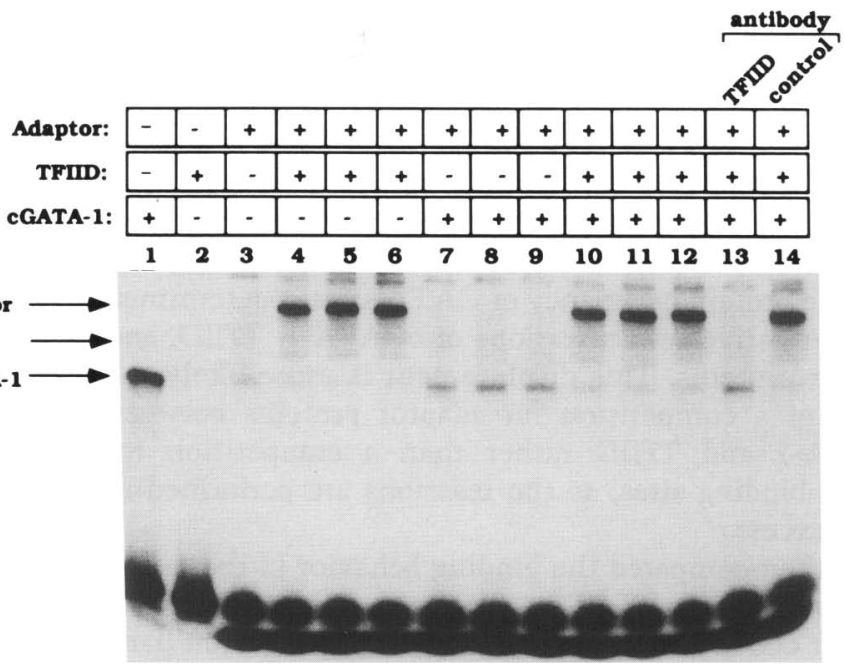

Figure 6. Gel mobility-shift analysis of cGATA-1 and TFIID displacement. Affinity-purified cGATA-1 and bacterially expressed hTFIID were incubated with ${ }^{32} \mathrm{P}$-end-labeled oligonucleotides containing the -30 GATA sequence, unless otherwise indicated, using the conditions described in Fig. 2. $(A \mid$ cGATA-1 and TFIID do not form a complex together on GATA DNA sequences. The following proteins were incubated with ${ }^{32}$ P-labeled GATA oligonucleotides: no protein (lane 1); 2 ng of cGATA-1 (lane 2); $5 \mathrm{ng}$ of hTFIID (lane 3); $5 \mathrm{ng}$ of hTFIID plus $2 \mathrm{ng}$ of cGATA-1 (lane 4); $5 \mathrm{ng}$ of cGATA-1 (lane 5). (B) TFIID binds efficiently to GATA DNA in the presence of adaptor proteins. ${ }^{32}$ P-labeled GATA oligonucleotides were incubated with the following proteins: $2 \mathrm{ng}$ of cGATA-1 (lane 1); $5 \mathrm{ng}$ of hTFIID (lane 2); $20 \mathrm{ng}$ of DNA-cellulose $/ 25 \mathrm{mM}\left(\mathrm{NH}_{4}\right)_{2} \mathrm{SO}_{4}$ fraction (DC/25 mM) (lane 3); $5 \mathrm{ng}$ of hTFIID plus 10,20 , and $40 \mathrm{ng}$ of DC/25 mM (lanes 4-6); $2 \mathrm{ng}$ of cGATA-1 plus 10, 20, and $40 \mathrm{ng}$ of DC/25 mM (lanes 7-9); $5 \mathrm{ng}$ of hTFID and $2 \mathrm{ng}$ of cGATA-1 plus 10,20 , and $40 \mathrm{ng}$ of DC/25 mM (lanes 10-12); $5 \mathrm{ng}$ of hTFIID and $2 \mathrm{ng}$ of cGATA-1 plus 20 $\mathrm{ng}$ of $\mathrm{DC} / 25 \mathrm{~mm}$ after incubation for $1 \mathrm{hr}$ at $0^{\circ} \mathrm{C}$ with antisera to hTFIID (lane 13) or antisera to an unrelated transcription factor, HIP (lane 14). (C) TFIID and adaptor proteins displace cGATA-1 from - 30 GATA DNA. The following proteins were incubated with ${ }^{32}$ P-labeled GATA oligonucleotides: 2 ng of cGATA-1 (lane 1); $20 \mathrm{ng}$ of DC/25 mM plus $5 \mathrm{ng}$ of hTFIID, $5 \mathrm{ng}$ of Spl or $6 \mathrm{ng}$ of Jun (lanes 2-4); $20 \mathrm{ng}$ of DC/25 mM and $5 \mathrm{ng}$ of hTFIID plus 2,5 , and $7 \mathrm{ng}$ of cGATA-1 (lanes 5-7). The following proteins were incubated with ${ }^{32}$ P-labeled TATA oligonucleotides: 5 ng of hTFIID (lane 1); $2 \mathrm{ng}$ of cGATA-1 (lane 2); $20 \mathrm{ng}$ of DC/25 mM (lane 10); $20 \mathrm{ng}$ of DC/25 mM plus $5 \mathrm{ng}$ of hTFIID (lane 11); $20 \mathrm{ng}$ of DC/25 $\mathrm{mM}$ and $5 \mathrm{ng}$ of hTFID plus $2 \mathrm{ng}$ of cGATA-1 (lane 12). The following proteins were incubated with ${ }^{32} \mathrm{P}$-labeled GG oligonucleotides (lane 13) or SSE oligonucleotides (lane 14): $20 \mathrm{ng}$ of DC/25 mm and $5 \mathrm{ng}$ of hTFIID plus $2 \mathrm{ng}$ of cGATA-1.

complex has no effect on the mobility of this complex, but its own binding is eliminated almost completely (lanes 10-12). This indicates that cGATA-1 is not a component of the hTFIID-adaptor complex and that this complex is a potent inhibitor of cGATA-1 binding. The hTFIID-adaptor complex is specifically disrupted by an antibody to hTFIID (lane 13), which restores some of the cGATA-1/GATA binding, but not by a control antibody to an unrelated protein (lane 14). As shown in Figure 6C, the association between the adaptor proteins and hTFIID on the GATA site is specific, because other DNA-bind- ing proteins such as Spl (lane 3) or Jun (lane 4) fail to form a high-molecular-weight complex when combined with the adaptor fraction.

Because the decrease of cGATA-1 binding in the presence of the hTFIID-adaptor complex was so striking, we varied the concentration of CGATA-1 in these reactions to examine the dynamics of interaction between these two complexes. At low cGATA-1 concentrations, the hTFIID-adaptor complex is present in high abundance while cGATA-1 binding is effectively eliminated (Fig. 6C; cf. lanes 1 and 5). As the concentration of cGATA-1 
increases, a change in the relative abundance of the hTFIID-adaptor complex and the cGATA-1/GATA complex is observed (lane 6), such that at the highest cGATA-1 levels the hTFIID-adaptor complex is negligible while the cGATA-1/GATA complex is efficiently formed (lane 7). These results suggest that there is an active displacement of CGATA-1 or TFIID binding and that the protein occupancy of GATA sites is determined by the relative concentrations of cGATA-1, TFIID, and adaptor proteins. This displacement is more likely the result of a competition for adaptor proteins between cGATA-1 and TFIID rather than a competition for GATA-binding sites, as the reactions are performed in DNA excess.

We then compared the binding behavior of these proteins on canonical TATA sites. As shown in Figure 6C, neither cGATA-1 (lane 9) nor the adaptor fraction (lane 10) binds to TATA oligonucleotides, and cloned hTFIID binds weakly (lane 8). However, when hTFIID and the adaptor proteins are combined, a high-molecular-weight complex is formed (lane 11) that comigrates with the hTFIID-adaptor complex formed on GATA oligonucleotides (lane 2). The addition of cGATA-1 has no effect on the hTFIID-adaptor complex (lane 12), and the complex does not form on nonspecific DNA sites such as GG (lane 13) or SSE (lane 14). The hTFIID and adaptor proteins bind much more efficiently on TATA than on GATA sites, and the observation that the two complexes comigrate supports, although does not conclusively prove, the idea that the protein composition on the two DNA sites is the same. Thus, at this time, there is no evidence to invoke the existence of different adaptors associating with TFIID on GATA and TATA boxes, although this remains a possibility. The further characterization of the adaptor proteins is currently in progress.

\section{cGATA-1 mediates $\beta$-globin promoter-enhancer interaction}

A summary of the binding data presented in the preceding section is shown in Figure 7 . The erythroid-specific protein cGATA- 1 regulates $\beta$-globin gene expression by binding to a distal, $3^{\prime}$ enhancer and to a specialized TATA box in the promoter. Although the exact mechanism is unknown, we speculate that cGATA-1 at the -30 GATA site forms a complex with itself or one of several other proteins bound to the enhancer through DNA loop formation. A model similar to this was originally proposed by Gallarda et al. (1989). This structure is recognized by TFIID, in combination with adaptor proteins, and cGATA-1 is displaced from the - 30 GATA box to allow transcriptional initiation. The role of cGATA-l interaction with a site that mediates TFIID function may be to enable the distal enhancer to regulate the transcriptional initiation complex. Because cGATA-1 is a tissue-specific protein, this requirement imposes an erythroid-specific level of control on enhancer-dependent $\beta$-globin gene expression. The proposed structure between the promoter and enhancer at the initiation site results in a highly active promoter and

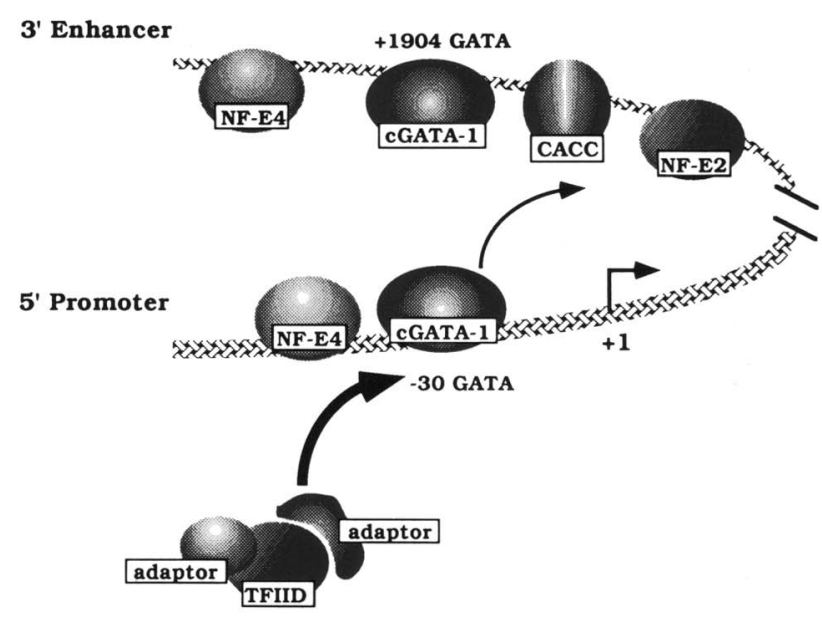

Figure 7. Model for cGATA-1 regulation of enhancer-dependent transcription. Schematic diagram showing the proposed relationship between cGATA-1, TFIID, and adaptor proteins at the specialized -30 GATA initiation site. This model suggests that the regulation of the transcriptional initiation complex by the erythroid-specific $\beta$-globin enhancer occurs in discrete stages. First, cGATA-1 at the - 30 GATA box interacts with proteins bound to the distal enhancer to establish a stable interaction between these two control regions. Second, TFIID and adaptor proteins displace cGATA- 1 from the -30 box to form an active initiation complex that is now regulated by the erythroid-specific enhancer. Mutation of the -30 site to a canonical TATA box, which cannot bind CGATA-1, significantly reduces the ability of the TFIID initiation complex to respond to the tissue-specific enhancer.

an efficient mechanism by which the enhancer can activate expression. If the - 30 GATA box is modified to a canonical TATA sequence, the binding affinity of the TFIID-adaptor complex increases but cGATA-1 cannot interact with this site. This does not alter the efficiency of the promoter, but enhancer-dependent expression is markedly decreased. This suggests that the high-affinity interaction of cGATA- 1 at -30 is critical for establishing promoter-enhancer interaction prior to the formation of an active initiation complex.

\section{Discussion}

The tissue-specific DNA-binding protein cGATA-1 interacts with the control regions of many erythroid-specific genes (Plumb et al. 1989), suggesting that it has a critical role in their regulation. This protein has been characterized in RBCs from several different species (Evans and Felsenfeld 1989; Tsai et al. 1989) and could represent a switch factor that is involved in the determination or maintenance of the erythroid phenotype. In these studies we examined the mechanism of action of cGATA-1 on the transcriptional regulation of the chick $\beta$-globin gene. We present evidence that cGATA-1 regulates both the promoter and the distal, $3^{\prime}$ enhancer through interaction with the TATA box. The $\beta$-globin gene family contains a specialized TATA sequence at - 30 (GATAAA in chick and CATAAA in human). cGATA-1, purified from chick erythrocytes, interacts 
with the GATA sequence in the chick $\beta$-globin enhancer as well as in the promoter. Modifications of the -30 GATA sequence that eliminate cGATA-1 but not TFIID binding have no effect on promoter activity, as measured by in vitro transcription using chick erythroid extracts, but significantly decrease enhancer-dependent transcription in transfected chick embryonic RBCs. This indicates that cGATA-1 does not function as a transcriptional activator when bound to the - 30 GATA box but is instead required to mediate distal enhancer activation of the promoter. This presumably occurs through the formation of a DNA loop between the two control regions. Interestingly, the cGATA-1-binding site within the enhancer functions as a TATA box when placed at the canonical location in the $\beta$-globin promoter. Thus, the protein-DNA complex that regulates a tissue-specific enhancer can also function through a specialized TATA element. Moreover, cGATA-1-binding sites in each control region must be functional for the $\beta$-globin gene to be expressed. Mutations in the cGATA-1 site of the enhancer have been shown to severely reduce the expression of $\beta$-globin CAT constructs (Reitman and Felsenfeld 1988).

Both TFIID and CGATA-1 function through the -30 GATA box and are necessary components of enhancerdependent $\beta$-globin transcription in erythroid cells. Our data demonstrate that these two proteins do not form a complex together but occupy GATA sites at different times. Thus, cGATA-1 does not appear to function in a manner similar to the adenovirus protein ElA, which can directly interact with TFIID and mediate activation by other transcription factors (Horikoshi et al. 1991; Lee et al. 1991). The binding of TFIID to the - 30 GATA site requires the addition of non-DNA-binding adaptor proteins because cloned hTFIID has very low affinity for GATA sequences. The TFIID-adaptor complex then interacts with cGATA-1 and displaces it from GATA-binding sites. At higher protein levels, cGATA-l can similarly displace the TFIID-adaptor complex. This indicates that the occupancy of the - 30 GATA box is carefully regulated by the relative concentrations of cGATA-1, TFIID, and adaptor proteins. Whether the adaptors that we describe are similar to the coactivator or adaptor proteins that mediate activation of the basal transcriptional machinery by other regulatory proteins (Berger et al. 1990; Kelleher et al. 1990; Pugh and Tiian 1990; Meisterernst et al. 1991) or represent the class of factors known as TAFs (Dynlacht et al. 1991) remains to be determined. We propose that the - 30 GATA box is occupied by cGATA-1 and TFIID at different times to first establish an interaction between the promoter and enhancer and then to form an active transcriptional initiation complex that is enhancer dependent. The purpose of incorporating cGATA-1 into the initiation site through the specialized TATA box may be to enable the TFIID complex to be regulated by the distal enhancer. By this mechanism, erythroid-specific and enhancer-dependent control of the initiation complex is imparted through a specialized TATA box. In support of this, a recent study demonstrated that mutation of the -30
GATA site in the rat platelet factor 4 gene to a canonical TATA element decreased tissue-specific expression in megakaryocytes, perhaps by rendering the promoter less responsive to the megakaryocyte-specific enhancer that is associated with this gene (Ravid et al. 1991).

Compelling evidence for promoter-enhancer interactions occurring through the TATA sequence comes from studies on the Drosophila alcohol dehydrogenase (Adh) gene (Corbin and Maniatis 1989). This gene is controlled by two promoters that are differentially activated by two separate enhancers at distinct developmental stages. Regulation is thought to occur through different TATA motifs within each promoter that determine the specificity of interactions with the appropriate enhancer. The investigators propose that either two separate TATA factors bind to each promoter or that a single TATA factor interacts differentially with the two motifs. Recent experiments have shown that the muscle-specific enhancer upstream of the human myoglobin gene is functional only with the TATA sequence 'TATAAAA', present in the myoglobin promoter. When this sequence is changed to that of the SV40 promoter, 'TATTTAT', the myoglobin enhancer no longer activates transcription (Wefald et al. 1990). A similar situation may exist in the chick $\beta$-globin gene if the cGATA-1/GATA complexes in the promoter and enhancer are required to mediate functional interaction between these two elements. Our data suggest that a sequence change to TATA destroys this interaction.

The functional distinction of multiple classes of TATA elements has been demonstrated in several studies. For example, experiments involving the human Hsp70 gene have shown that a conversion of the normal TATA sequence to that of the SV40 'TATTTAT' results in transcription that is no longer inducible by E1A / $\mathrm{Si}$ mon et al. 1988). In yeast, two distinct TATA boxes have been identified in the his 3 promoter, $T_{R}$ and $T_{C}$, which appear to interact with different proteins /Chen and Struhl 1988). These TATA elements respond differentially to the transcriptional activators GCN4 and GAL4 such that only the $T_{R}$ TATA sequence can be induced by the upstream activators (Harbury and Struhl 1989). Recently, the pituitary-specific transcription factor GHF-1 has been shown to regulate expression of the growth hormone gene through a 15-bp region that includes the TATA box (McCormick et al. 1991). Taken together, these examples of TATA box heterogeneity indicate that TFIID activity can be modulated by differential interactions with non-TATA factors that bind to adjacent or overlapping DNA sequences. These factors may change the structure of the initiation complex and facilitate the functional interaction with regulatory proteins that control different levels of gene expression.

We propose that an initial step in $\beta$-globin gene expression is the interaction of cGATA-1 bound to the -30 GATA box with cGATA-1, or other proteins, bound to the $3^{\prime}$ enhancer. This interaction may have a critical role in allowing the two control regions to communicate with each other, presumably by DNA loop formation. Once the DNA loop is formed, TFIID and adaptor pro- 
teins displace cGATA-1 and produce an active initiation complex that is under the control of the erythroid-specific enhancer. Because cGATA-1 is present at all stages of erythroid development, this loop may form in primitive RBCs long before the $\beta$-globin gene is expressed. Alternatively, in definitive RBCs this connection between the two control regions could be stabilized by the binding of other proteins to the promoter and enhancer, such as the erythroid stage-specific factor NF-E4 (Gallarda et al. 1989). Interestingly, the cGATA-1-enhancer complex is situated between the $\beta$ - and $\epsilon$-globin genes and controls their expression at different stages of erythroid development (Choi and Engel 1988; Nickol and Felsenfeld 1988). The NF-E4 protein has been implicated in causing the regulated switch in transcription from the $\epsilon$ - to the $\beta$-globin gene by altering the interaction of the $\beta$-globin enhancer with the promoters for each of these templates (Gallarda et al. 1989). This factor has been shown previously to be an activator of $\beta$-globin gene transcription in an erythroid cell-free system (Emerson et al. 1989).

A comparison of TATA elements in the $\beta$-globin gene family indicates that both the embryonic, $\rho$ and $\epsilon$, and adult $\beta$-globin promoters contain cGATA- 1 binding sites at -30 and not elsewhere in the near vicinity. In contrast, the $\beta$-hatching and $\alpha^{1)}$-globin genes contain a canonical TATA sequence at -30 and have cGATA-1 sites within 60 bp upstream (Dodgson et al. 1983). The $\alpha$-globin genes are regulated much differently than the $\beta$-globin family, because they are expressed throughout erythropoeisis rather than at discrete stages. We suggest that CGATA-1 may regulate erythroid genes having either TATA or GATA sequences at -30 by different mechanisms. For example, in the $\alpha^{1)}$-globin gene, the TFIID initiation complex could be under erythroid-specific control if cGATA-1 is required to activate it from nearby sites. In this case, cGATA-1 would function as a direct activator of TFIID. In genes such as $\beta-, \rho-$, and $\epsilon$-globin, cGATA-1 binds to the - 30 GATA element and may affect the activity of TFIID indirectly by enabling it to interact with a distal enhancer. Thus, cGATA-1 is a transcription factor that may have different mechanisms of action depending on where it binds and which proteins it interacts with.

The erythroid GATA-1 protein is part of a multigene family that includes members that also regulate other tissue-specific enhancer regions. For example, GATA-3 is abundantly expressed in T lymphocytes and brain cells (Yamamoto et al. 1990; Ho et al. 1991) and is involved in the control of the TCR $\delta$-chain enhancer (Ko et al. 1991). It will be interesting to compare the mechanism by which other members of the GATA family regulate promoter-enhancer activity with that of the erythroid-specific cGATA-1 factor.

\section{Materials and methods}

\section{Plasmid constructions}

The standard chick $\beta$-globin gene template (pUC18ABC/ $\Delta 1$ ) used in the in vitro transcription experiments contains the up- stream chicken $\beta^{A}$-globin promoter (to -407 ), a 17-bp insert at position +46 to mark the gene, and $1.5 \mathrm{~kb}$ of $3^{\prime}$-flanking sequences, which includes the entire $\beta$-globin enhancer region (Emerson et al. 1989). $\beta^{\mathrm{A}}$-Globin genes containing modified TATA boxes were derived from this parental plasmid $(\Delta 1)$. The wild-type GATA box sequence at -30 was mutated from GATA to GAGGA in $\triangle 1 /$ GG and to TATAA in $\triangle 1 / T A T A$. The plasmid $\Delta$ l/RIV contained the GATA (enhancer) region IV site (TTGCAGATAAACAT, +1899 to +1911 ) in place of the GATA box sequence (GAGGCGATAAAAG, -35 to -23 ) in the promoter. These promoter mutations were constructed by synthesizing 84 -bp oligonucleotides $(-94$ to -10$)$ containing the three sequence changes. The oligonucleotides were synthesized to contain overhanging ends for ApaI $\left(5^{\prime}\right)$ and EagI $\left(3^{\prime}\right)$ restriction sites. Each mutated oligonucleotide was then inserted into the ApaI $(-94)$ and EagI (-10) sites of the parental plasmid $p U C 18 \mathrm{ABC} / \Delta \mathrm{l}$ for in vitro transcription templates or into a plasmid, $\mathrm{p} 8 \mathrm{~A}$, which contains only $\beta$-globin promoter sequences $(-407$ to +196$)$ for DNase I protection studies.

$\beta$-Globin templates used to transfect primary chick erythrocytes were derived from AcatE30 with the $3^{\prime} \beta$-globin enhancer extending from +1814 to +2231 and the $\beta$-globin promoter from -1000 to +43 (Hesse et al. 1986). Acat is identical to AcatE30 except that the 417-bp 3' enhancer fragment is deleted. The RSV-CAT control plasmid contains the RSV LTR linked to the bacterial CAT gene. The plasmids AcatE/GG, AcatE/TATA, and AcatE/RIV contain modified GATA boxes as described for $\Delta 1 / G G, \Delta 1 / T A T A$, and $\Delta 1 / R I V$, respectively. These were constructed by isolating the EcoRI-EagI $\left(5^{\prime}-\beta\right)$ fragment from each corresponding p8A mutant and inserting it into the corresponding site of AcatE30. Two DNA fragments from an EcoRI and EagI digest of AcatE30 were isolated: One contains the sequences from -10 of the $\beta$-globin promoter to +250 of the CAT gene ( $\left.\mathrm{CAT}^{\prime}\right)$, and the second contains the remaining enhancervector sequences (Enh-vector). The mutated p $8 A 5^{\prime}-\beta$ and CAT' fragments were then ligated together, digested with EcoRI, and ligated to the Enh-vector fragment. The resulting AcatE derivatives, containing mutations in the - 30 GATA box, were digested with Pstl to determine the orientation of the $5^{\prime}-\beta / \mathrm{CAT}^{\prime}$ fragment.

\section{Preparation and purification of protein extracts}

Nuclear protein extracts from adult and 11-day chick erythrocytes (McIntyre Poultry, San Diego, CA) were prepared as described previously (Emerson et al. 1987). High-affinity DNAbinding proteins from staged erythrocytes were obtained by chromatography of a $0.42 \mathrm{M} \mathrm{KCl}$ nuclear extract on calf thymus DNA-cellulose (Sigma) and eluting with $0.25 \mathrm{M}\left(\mathrm{NH}_{4}\right)_{2} \mathrm{SO}_{4}$ (DC/250 fraction) as described in Emerson and Felsenfeld (1984). Purified cGATA-1 protein was prepared by chromatographing a DC/250 preparation on a sequence-specific GATA (enhancer) region IV DNA-affinity column according to the method of Kadonaga and Tjian (1986).

\section{DNase protection analyses and gel mobility shifts}

DNase protection experiments were conducted as described by Emerson et al. (1987). The analysis of cGATA-1 and yeast or hTFIID interaction with $5^{\prime}{ }^{32} \mathrm{P}$-labeled oligonucleotides to various TATA sequences was performed by incubation of protein and DNA in a buffer containing $20 \mathrm{mM}$ HEPES (pH 7.9), $50 \mathrm{~mm}$ $\mathrm{NaCl}, 5 \mathrm{~mm} \mathrm{MgCl}_{2}, 100 \mu \mathrm{g} / \mathrm{ml}$ of BSA, 6\% glycerol, $1 \mathrm{~mm} \mathrm{DTT}$, and $0.025 \% \mathrm{NP}-40$. Binding was allowed to proceed for $30 \mathrm{~min}$ at $30^{\circ} \mathrm{C}$. The reactions were then analyzed by electrophoresis on 
a $5 \%$ polyacrylamide gel containing $0.5 \times \mathrm{TBE}, 0.05 \% \mathrm{NP}-40$, $5 \%$ glycerol, $0.5 \mathrm{mM}$ DTT, and $1 \mathrm{mM}$ EDTA $(\mathrm{pH} 7.5)$. Gels were run in $0.5 \times \mathrm{TBE}$ and $1 \mathrm{mM} \operatorname{EDTA}(\mathrm{pH} 7.5)$ for $1 \mathrm{hr}$ at $250 \mathrm{~V}$ at $4^{\circ} \mathrm{C}$.

Oligonucleotides used in these experiments were synthesized by Operon Technologies (Alameda, CA) and are as follows:

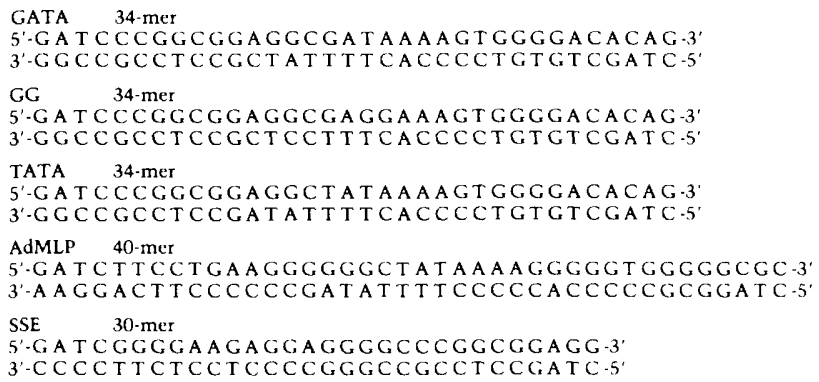

\section{In vitro transcription}

Conditions for transcription and the preparation of extracts from 11-day chick erythrocytes were identical to that described previously (Emerson et al. 1989). The preparation of whole-cell transcription extracts from HeLa cells was according to a modification of the procedure of Dignam et al. (1983). Reaction products were analyzed by $\mathrm{Sl}$ nuclease digestion and electrophoresed on $8 \%$ polyacrylamide/urea/TBE gels. Transcription reactions were quantitated by excising the ${ }^{32}$ P-labeled 94-base RNA transcript, and radioactivity was determined by scintillation counting.

To analyze TFIID transcriptional complementation, a modification of the procedure described by Nakajima et al. (1988) was used. Whole-cell HeLa extracts were heated at $47^{\circ} \mathrm{C}$ for $12 \mathrm{~min}$ to inactivate TFIID activity. These extracts were then complemented with rabbit reticulocyte lysate programmed with in vitro-transcribed RNA from cGATA-1 or hTFIID clones. Control lysates were not programmed with mRNA but were otherwise treated identically to the hTFID and cGATA-1-programmed reactions. In vitro-synthesized RNAs were prepared from expression vectors of hTFIID (hIID, R. Roeder) and cGATA-1 (E36c/33d NNB9, D. Engel) using a Riboprobe System II T7 polymerase kit (Promega, Madison, WI), and in vitro-translated proteins were synthesized using nuclease-treated rabbit reticulocyte lysate (Promega) according to the manufacturer's instructions.

\section{Transfections}

Primary erythrocytes isolated from the circulation of 10- to 1I-day chick embryos (McIntyre Poultry) were osmotically shocked by treatment with $0.25 \mathrm{M} \mathrm{NH}_{4} \mathrm{Cl}$ and transfected with various $\beta$-globin DNA constructs. Definitive erythroid cells $\left(3 \times 10^{7}\right.$ to $\left.5 \times 10^{7}\right)$ were transfected with $3 \mu \mathrm{g} / \mathrm{ml}$ of DNA according to the method of Hesse et al. (1986), as modified by Jackson et al. (1989). Following a $48-\mathrm{hr}$ incubation at $37^{\circ} \mathrm{C}$, the cells were processed and assayed for CAT activity using a standard protocol based on the method of Gorman et al. (1982).

\section{Acknowledgments}

We are indebted to Dr. Katherine Jones for a critical reading of the manuscript and her gift of antisera to the HIP protein; to Drs. M. Horikoshi and R. Roeder for their gift of purified yeast
TFIID and the yeast and human TFIID gene clones; to Dr. Arnie Berk for antisera to hTFIID; and to Dr. Doug Engel for his gift of the cGATA-1 clone. We also thank Dr. Lynn J. Ransone for providing Jun RNA and protein, as well as valuable technical advice. B.M.E. thanks Dr. Raquel M. Prieguez for her enthusiastic support of this work. This project was funded by a grant from the National Institutes of Health (GM38760). T.C.F. was supported by a Postdoctoral National Research Service grant (1F32HL/GM 07982) from the National Heart, Lung, and Blood Institute. B.M.E. is a Pew Scholar in the Biomedical Sciences.

The publication costs of this article were defrayed in part by payment of page charges. This article must therefore be hereby marked "advertisement" in accordance with 18 USC section 1734 solely to indicate this fact.

\section{References}

Berger, S.L., W.D. Cress, A. Cress, S.J. Triezenberg, and L. Guarente. 1990. Selective inhibition of activated but not basal transcription by the acidic activation domain of VP-16: Evidence for transcriptional adaptors. Cell 61: 1199-1208.

Brown, J.L. and V.M. Ingram. 1974. Structural studies on chick embryonic hemoglobins. J. Biol. Chem. 249: 3960-3972.

Bruns, G.A. and V.M. Ingram. 1973. The erythroid cells and hemoglobins of the chick embryo. Phil. Trans. R. Soc. Lond. B Biol. Sci. 266: 225-305.

Chapman, B.S. and A.J. Tobin. 1979. Distribution of developmentally regulated hemoglobins in embryonic erythroid populations. Dev. Biol. 69: 375-387.

Chen, W. and K. Struhl. 1988. Saturation mutagenesis of a yeast his3 "TATA element": Genetic evidence for a specific TATA-binding protein. Proc. Natl. Acad. Sci. 85: 269l2695.

Choi, O.B. and J.D. Engel. 1988. Developmental regulation of $\beta$-globin gene switching. Cell 55: 17-26.

Corbin, V. and T. Maniatis. 1989. The role of specific enhancerpromoter interactions in the Drosophila Adh promoter switch. Genes \& Dev. 3: 2191-2200.

Dignam, J.D., R.M. Lebovitz, and R.G. Roeder. 1983. Accurate transcription initiation by RNA polymerase II in a soluble extract from isolated mammalian nuclei. Nucleic Acids Res. 11: $1475-1489$.

Dodgson, J.B., S.J. Stadt, O.R. Choi, M. Dolan, H.D. Fischer, and J.D. Engel. 1983. The nucleotide sequence of the embryonic chicken $\beta$-type globin genes. /. Biol. Chem. 258: 1268512692.

Dynlacht, B.D., T. Hoey, and R. Tiian. 1991. Isolation of coactivators associated with the TATA-binding protein that mediate transcriptional activation. Cell 66: 563-576.

Emerson, B.M. and G. Felsenfeld. 1984. Specific factor conferring nuclease hypersensitivity at the $5^{\prime}$ end of the chicken adult $\beta$-globin gene. Proc. Natl. Acad. Sci. 81: 95-99.

Emerson, B.M., C.D. Lewis, and G. Felsenfeld. 1985. Interaction of specific nuclear factors with the nuclease-hypersensitive region of the chicken adult $\beta$-globin gene: Nature of the binding domain. Cell 41: 21-30.

Emerson, B.M., J.M. Nickol, P.D. Jackson, and G. Felsenfeld. 1987. Analysis of the tissue-specific enhancer at the $3^{\prime}$ end of the chicken adult $\beta$-globin gene. Proc. Natl. Acad. Sci. 84: $4786-4790$.

Emerson, B.M., J.M. Nickol, and T.C. Fong. 1989. Erythroidspecific activation and derepression of the chick $\beta$-globin promoter in vitro. Cell 57: 1189-1200.

Evans, T. and G. Felsenfeld. 1989. The erythroid-specific transcription factor Eryfl: A new finger protein. Cell 58: 877- 
885.

Evans, T., M. Reitman, and G. Felsenfeld. 1988. An erythrocytespecific DNA-binding factor recognizes a regulatory sequence common to all chicken globin genes. Proc. Natl. Acad. Sci. 85: 5976-5980.

Gallarda, J.L., K.P. Foley, Z. Yang, and J.D. Engel. 1989. The $\beta$-globin stage selector element factor is erythroid-specific promoter/enhancer binding protein NF-E4. Genes \& Dev. 3: $1845-1859$.

Gorman, C.M., L.F. Moffat, and B.H. Howard. 1982. Recombinant genomes which express chloramphenicol acetyltransferase in mammalian cells. Mol. Cell. Biol. 2: 1044-1051.

Harbury, P.A.B. and K. Struhl. 1989. Functional distinctions between yeast TATA elements. Mol. Cell. Biol. 9: 52985304.

Hesse, J.E., J.M. Nickol, M.R. Lieber, and G. Felsenfeld. 1986. Regulated gene expression in transfected primary chicken erythrocytes. Proc. Natl. Acad. Sci. 83: 4312-4316.

Ho, I.C., L.-H. Yang, G. Morle, and J.M. Leiden. 1989. A T cell specific transcriptional enhancer element $3^{\prime}$ of $\mathrm{C} \alpha$ in the human $\mathrm{T}$ cell receptor $\alpha$ locus. Proc. Natl. Acad. Sci. 86: 6714-6718

Ho, I.C., P. Vorhees, N. Marin, B.K. Oakley, S.-F. Tsai, S.H. Orkin, and J.M. Leiden. 1991. Human GATA-3: A lineagerestricted transcription factor that regulates the expression of the T cell receptor $\alpha$ gene. EMBO /. 10: 1187-1192.

Horikoshi, N., K. Maguire, A. Kralli, E. Maldonado, D. Reinberg, and R. Weinmann. 1991. Direct interaction between adenovirus ElA protein and the TATA box binding transcription factor IID. Proc. Natl. Acad. Sci. 88: 5124-5128.

Jackson, P.D., T. Evans, J.M. Nickol, and G. Felsenfeld. 1989. Developmental modulation of protein binding to $\beta$-globin gene regulatory sites within chicken erythrocyte nuclei. Genes \& Dev. 3: 1860-1873.

Kadonaga, I.T. and R. Tiian. 1986. Affinity purification of sequence-specific DNA binding proteins. Proc. Natl. Acad. Sci. 83: 5889-5893.

Kelleher, R.J. III, P.M. Flanagan, and R.D. Kornberg. 1990. A novel mediator between activator proteins and the RNA polymerase II transcription apparatus. Cell 61: 1209-1215.

Ko, L.J., M. Yamamoto, M.W. Leonard, K.M. George, P. Ting, and J.D. Engel. 1991. Murine and human T-lymphocyte GATA-3 factors mediate transcription through a cis-regulatory element within the human T-cell receptor $\delta$ gene enhancer. Mol. Cell. Biol. 11: 2778-2784.

Lee, W.S., C.C. Kao, G.O. Bryant, X. Liu, and A.J. Berk. 1991. Adenovirus ElA activation domain binds the basic repeat in the TATA box transcription factor. Cell 67: 365-376.

Lewis, C.D., S.P. Clark, G. Felsenfeld, and H. Gould. 1988. An erythrocyte-specific protein that binds to the poly(dG) region of the chicken $\beta$-globin gene promoter. Genes \& Dev. 2: 863-873.

McCormick, A., H. Brady, J. Fukushima, and M. Karin. 1991. The pituitary-specific regulatory gene GHF1 contains a minimal cell type-specific promoter centered around its TATA box. Genes \& Dev. 5: 1490-1503.

McGhee, J.D., W.I. Wood, M. Dolan, J.D. Engel, and G. Felsenfeld. 1981. A 200 base pair region at the $5^{\prime}$ end of the chicken adult $\beta$-globin gene is accessible to nuclease digestion. Cell 27: 45-55.

Meisterernst, M., A.L. Roy, H.M. Lieu, and R.G. Roeder. 1991. Activation of class II gene transcription by regulatory factors is potentiated by a novel activity. Cell 66: 981-993.

Nakajima, N., M. Horikoshi, and R.G. Roeder. 1988. Factors involved in specific transcription by mammalian RNA polymerase II: purification, genetic specificity, and TATA box- promoter interactions of TFIID. Mol. Cell. Biol. 8: 40284040.

Nickol, J.M. and G. Felsenfeld. 1988. Bidirectional control of the chicken $\beta$ - and $\epsilon$-globin genes by a shared enhancer. Proc. Natl. Acad. Sci. 85: 2548-2552.

Pevny, L., M.C. Simon, E. Robertson, W.H. Klein, S.-F. Tsai, V. D'Agati, S.H. Orkin, and F. Costantini. 1991. Erythroid differentiation in chimaeric mice blocked by a targeted mutation in the gene for transcription factor GATA-1. Nature 349: 257-260.

Plumb, M.A., V.V. Lobanenkov, R.H. Nicolas, C.A. Wright, S. Zavou, and G.H. Goodwin. 1986. Characterisation of chicken erythroid nuclear proteins which bind to the nuclease hypersensitive regions upstream of the adult $\beta$ - and hatching $\beta$-globin genes. Nucleic Acids Res. 14: 7675-7693.

Plumb, M.A., J. Frampton, H. Wainwright, M. Walker, K. Macleod, G. Goodwin, and P. Harrison. 1989. GATAAG; a ciscontrol region binding an erythroid-specific nuclear factor with a role in globin and nonglobin gene expression. Nucleic Acids Res. 17: 73-91.

Pugh, B.F. and R. Tiian. 1990. Mechanism of transcriptional activation by $\mathrm{Sp} 1$ : Evidence for coactivators. Cell 61: 11871197.

Ravid, K., T. Doi, D.L. Beeler, D.J. Kuter, and R.D. Rosenberg. 1991. Transcriptional regulation of the rat platelet factor 4 gene: Interaction between an enhancer/silencer domain and the GATA site. Mol. Cell. Biol. 11: 6116-6127.

Redondo, J.M., S. Hata, C. Brocklehurst, and M.S. Krangel. 1990. A T cell-specific transcriptional enhancer within the human $T$ cell receptor $\delta$ locus. Science 247: 1225-1229.

Reitman, M. and G. Felsenfeld. 1988. Mutational analysis of the chicken $\beta$-globin enhancer reveals two positive-acting domains. Proc. Natl. Acad. Sci. 85: 6267-6271.

Simon, M.C., T.M. Fisch, B.J. Benecke, J.R. Nevins, and N. Heintz. 1988. Definition of multiple, functionally distinct TATA elements, one of which is a target in the hsp70 promoter for E1A regulation. Cell 52: 72.3-729.

Stalder, J., A. Larsen, J.D. Engel, M. Dolan, M. Groudine, and H. Weintraub. 1980. Tissue-specific DNA cleavages in the globin chromatin domain introduced by DNase I. Cell 20: $451-460$.

Trainor, C.D., T. Evans, G. Felsenfeld, and M.S. Boguski. 1990. Structure and evolution of a human erythroid transcription factor. Nature 343: 92-96.

Tsai, S.-F., D.I.K. Martin, L.I. Zon, A.D. D'Andrea, G.G. Wong, and S.H. Orkin. 1989. Cloning of cDNA for the major DNA binding protein of the erythroid lineage through expression in mammalian cells. Nature 339: 446-451.

Wefald, F.C., B.H. Devlin, and R.S. Williams. 1990. Functional heterogeneity of mammalian TATA-box sequences revealed by interaction with a cell-specific enhancer. Nature 344 : 260-262.

Wilson, D.B., D.M. Dorfman, and S.H. Orkin. 1990. A nonerythroid GATA-binding protein is required for function of the human preproendothelin-1 promoter in endothelial cells. Mol. Cell. Biol. 10: 4854-4862.

Winoto, A. and D. Baltimore. 1989. A novel, inducible and T cell-specific enhancer located at the $3^{\prime}$ end of the $\mathrm{T}$ cell receptor $\alpha$ locus. EMBO I. 8: 729-733.

Yamamoto, M., L.J. Ko, M.W. Leonard, H. Beug, S.H. Orkin, and J.D. Engel. 1990. Activity and tissue-specific expression of the transcription factor NF-E1 multigene family. Genes \& Dev. 4: 1650-1662. 


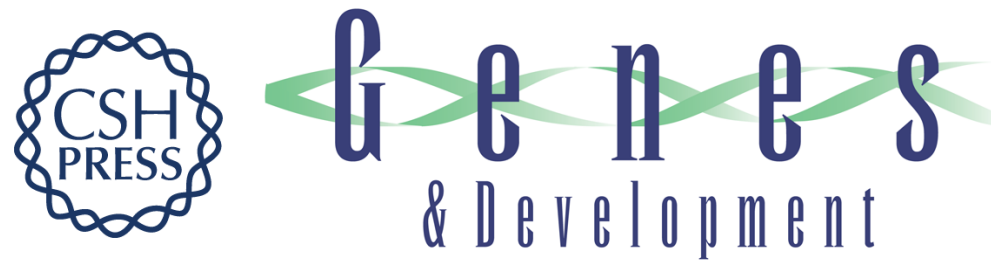

\section{The erythroid-specific protein cGATA-1 mediates distal enhancer activity through a specialized beta-globin TATA box.}

T C Fong and B M Emerson

Genes Dev. 1992, 6:

Access the most recent version at doi:10.1101/gad.6.4.521

References This article cites 49 articles, 25 of which can be accessed free at:

http://genesdev.cshlp.org/content/6/4/521.full.html\#ref-list-1

License

Email Alerting

Service

Receive free email alerts when new articles cite this article - sign up in the box at the top right corner of the article or click here.

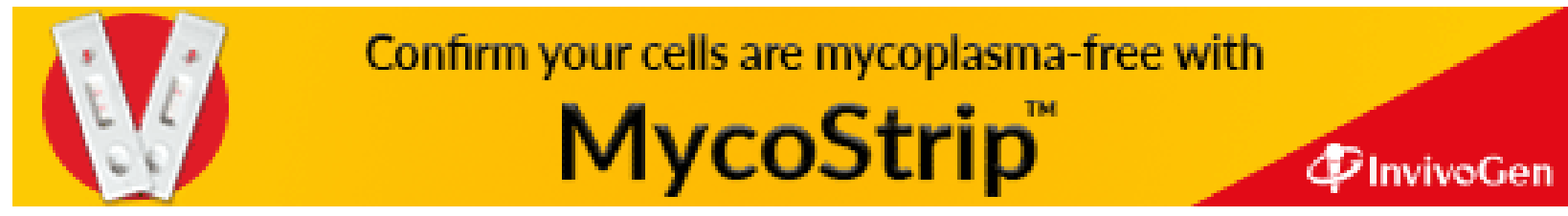

